\title{
The Welfare of Domestic Goats (Capra hircus) in a Zoo- Based Animal-Visitor Interaction Program
}

\author{
Margaret Ramont, Maureen Leahy, and Katherine A. Cronin*
}

Animal Welfare Science Program, Lincoln Park Zoo

*Corresponding author (Email: kcronin@lpzoo.org)

Citation - Ramont, M., Leahy, M., \& Cronin, K. A. (2021). The welfare of domestic goats (Capra hircus) in a zoobased animal-visitor interaction program. Animal Behavior and Cognition, 8(4), 493-506. https://doi.org/10.26451/abc.08.04.04.2021

\begin{abstract}
We investigated whether the welfare of domestic goats in an animal-visitor interaction experience at a zoo was affected by the presence and behavior of visitors. We considered how the number of visitors in the goats' habitat and visitor proximity to the goats impacted goat behavior. We also considered the goats' behavior toward visitors, use of retreat space, and whether the visitors' interaction style, specifically, how the visitors groomed the goats, was predictive of changes in the goats' behavior. We conducted $29 \mathrm{hr}$ of focal follows on 7 domestic goats (Capra hircus) at Lincoln Park Zoo, and analyzed data using mixed effects models. We found that goats preferred to be in the visitor yard as visitor numbers increased, and goat behaviors did not change as visitor numbers increased to the maximum allowed (16 people). There were no differences in rates of conspecific aggression or affiliation based on visitor presence or visitor interactions. However, there was a decrease in feeding and increase in selfmaintenance behaviors specifically while visitors were in close proximity and interacting with goats. Furthermore, visitor-directed behavior, specifically head tossing, was more common when visitors groomed goats in an improper way. Overall, this study demonstrates that domestic goat welfare was relatively unaffected by the simple presence of visitors when maximum visitor limits were in place and retreat options were available, but that goats were sensitive to visitor interaction styles. These findings support the idea that domestic goats may be appropriate candidates for human-visitor interaction programs under specific conditions.
\end{abstract}

Keywords - Visitor effect, Ambassador animals, Animal-visitor interactions, Petting zoo, Ungulate, Animal welfare

Many zoos and aquariums strive to evaluate and enhance the welfare of animals in their care. Although animal welfare is a multi-faceted concept with several circulating definitions (Veit \& Browning, 2021), the Five Domains Model of Animal Welfare originally proposed by Mellor and Reid (1994) has become a unifying influential framework that allows for the identification of factors likely to influence an animal's welfare status. Factors affect welfare through impacts on animals' mental domain, understood in terms of animals' affective experiences (e.g., Mellor, 2017; Mellor \& Beausoleil, 2015). The model has been updated as new advances in animal welfare science have emerged (Mellor \& Beausoleil, 2015); most recently, Mellor et al. (2020) provided an updated account of the model that highlights the varying effects that interactions between animals and humans may have on an animal's welfare status. By this account, interactions with humans will ultimately influence the welfare status of the animal dependent upon the mental, affective experience that those interactions generate within the animal.

Human-animal interactions in zoos and aquariums can take many forms, and past research has explored the effects of several types of human-animal relationships on the welfare of a wide range of species (Hemsworth et al., 2018; Melfi \& Hosey, 2018; Sherwen \& Hemsworth, 2019; Ward \& Sherwen, 
2018). Although it is difficult to extract general trends given small sample sizes and the diversity of contexts and species (Rodriguez et al., 2020; Spooner et al., 2021), one theme that emerges from this line of work is that animals tend to express different physiological and behavioral responses dependent upon the behavior of humans in their environment (reviewed in Cole \& Fraser, 2018; Waiblinger, 2018). Generally, animal responses differ depending on the way the human interacts with the animal. Negative interactions are characterized by quick approaches, rough handling, loud voices and/or unpredictable movements, and positive interactions are characterized by quiet and affiliative interactions, slow approaches and predicable movements (e.g., Breuer et al., 2003; Rushen, et al., 1999; Smith, 2014; Waiblinger et al., 2006). Similar patterns hold for familiar caretakers; positive human-animal relationships are more likely to develop if caretakers have regular visual contact, spend time feeding and talking with the animals, and limit aversive contact (Hosey \& Melfi, 2010, 2015; Melfi \& Hosey, 2018; Ward \& Melfi, 2015).

Several types of human-animal interactions are possible in a petting zoo environment. Often, in this kind of environment, a selection of domesticated or semi-domesticated species can come into close proximity with humans with direct physical contact and sanctioned feeding opportunities (Farrand et al., 2014). Petting zoos are common in zoological settings, and D'Cruze et al. (2019) reported "petting" interactions as the most common form of visitor interaction program in zoos worldwide. This analysis was based upon a systematic review of the websites of zoos and aquariums that are members of the World Association of Zoos and Aquariums (either directly or through regional associations). Within the Association of Zoos and Aquariums, the primary accrediting body for zoos and aquariums in North America, an estimated $61 \%$ of organizations showed a petting experience to their website visitors (D’Cruze et al., 2019). Here, we focus on how zoo visitors and their behavior are associated with changes in the welfare of domestic goats, a species common to petting zoos.

Behavioral and physiological responses in close proximity to humans may be related to the species' history of domestication. Goats were probably the first domesticated ruminant livestock species, estimated to have been domesticated approximately 10,000 years ago (Zeder \& Hesse, 2000). Domestication history may be related to animal welfare in human visitor interaction programs in zoos; Ramont et al. (2021) report that domesticated chickens showed little to no changes in behavioral indicators of welfare when they had the option to approach zoo visitors in a feeding program, and that greater visitor numbers did not predict chicken avoidance of visitor areas. Furthermore, in a recent study investigating guinea pig responses to zoo visitors, Powell et al. (2020) found that domesticated guinea pigs housed in an exhibit allowing them to be touched by visitors showed no systematic changes in glucocorticoids or body weight indicative of welfare compromise relative to when they were housed off exhibit without visitors touching them. Both Ramont et al. (2021) and Powell et al. (2020) interpret their zoo-based findings in light of research demonstrating that reduced behavioral and physiological responsiveness to potentially stressful stimuli, including human presence, is a common feature of domestication (e.g., Fallahsharoudi et al., 2015; Fraser \& Broom, 1990; Künzl \& Sachser, 1999; Price, 1984).

A few studies have investigated the impact of zoo visitor presence and visitor behavior on welfare indicators of domestic goats in petting zoo settings. Anderson et al. (2002) measured the aggressive and escape behaviors of African pygmy goats (Capra hircus) and Romanov sheep (Ovis aries) in relation to the availability of retreat space, and found that when the animals were provided with the opportunity to completely separate from guests in a full-retreat condition, the frequency of these behaviors was lower than when they did not have an option to completely separate. The authors also reported that as visitor density increased, so did aggressive and escape behaviors. In a later study, Anderson and colleagues (2004) found that more frequent touching was also associated with more aggressive and escape behaviors. Behavioral differences associated with retreat options, visitor density, and visitor behavior were more pronounced in the sheep than in the goats, however.

Later, Farrand et al. (2014) measured behavioral changes in various breeds of goats (Capra hircus), llamas (Llama glama) and Vietnamese pot-bellied pigs (Sus scrofa) in a petting zoo environment. In this study, greater visitor densities did not measurably impact the behavior of goats and llamas. The 
authors considered aggression, escape-related behaviors, feeding, resting and socializing with conspecifics. They also investigated whether animal behavior changed when visitors were provided with grooming brushes. Again, for goats, no significant changes were detected, and goats tolerated grooming for longer durations than the other two species. On dairy farms, goat welfare is related to the way that stockpersons physically interact with goats, and goats exposed to positive, physical attention ("gentling," in the farm welfare literature), show less reservation approaching a person in an experimental test of comfort than goats who have not experienced gentling (Jackson \& Hackett, 2007; Waiblinger et al., 2006). Taken together, these results demonstrate that while goats may be less measurably impacted by zoo visitors than other species under similar close contact conditions, their short- and long-term welfare is likely sensitive to the quality of their interactions with humans.

Here, we focus on how the welfare of domestic goats in a petting zoo environment is affected by the behavior of visitors who are provided close-contact access to the goats and the opportunity to groom them. In the program under study, the goats have continuous access to a retreat space that excludes visitors, and visitors were provided brushes to use to groom the goats. We consider how the number of visitors in the goats' habitat and visitor proximity to the goats impacts behavioral indicators of welfare, including changes in affiliative and agonistic interactions with conspecifics, self-maintenance behaviors, feeding behavior, and general activity including locomotion, exploration and object manipulation. We also consider the goats' behavior toward visitors, use of retreat space, and whether the visitors' interaction style (how the visitor grooms the goat) predicts changes in the goats' behavior. A decrease in affiliation, increase in aggression, and/or increase in the use of retreat space would suggest potential welfare compromise. Other behaviors are included to gain a descriptive understanding of behavioral change associated with visitors but are less directly or obviously linked to welfare status; these include feeding behavior, self-maintenance behaviors, and general activity. Given previous studies, we hypothesize that the goats will not show any overt behavioral changes in response to increasing visitor density, but that the behavior of goats will differ based on how visitors interact with the goats.

\section{Method}

\section{Subjects and Housing}

Seven adult male domestic goats of various breeds at Lincoln Park Zoo's Farm in the Zoo were the focus of this study. All of the goats were neutered and disbudded at a young age prior to their arrival at Lincoln Park Zoo, and the goat herd had been together since 2014. The habitat (Figure 1) was separated into three main areas: the outdoor yard $\left(62.4 \mathrm{~m}^{2}\right)$ the outdoor retreat area $\left(15.6 \mathrm{~m}^{2}\right)$, and the indoor retreat area or barn $\left(58.3 \mathrm{~m}^{2}\right)$. The outdoor yard was equipped with water, a mineral block, a shade structure and elevated rocks. Goats had access to all three areas during the day, and were housed in the indoor barn overnight (approximately 4PM to 10AM). The goats were fed hay, equine senior feed, and alfalfa and timothy cubes two times a day inside the barn: in the morning prior to opening to the public and in the afternoon after closing for the day. At 12PM, the yard was temporary closed to the public while hay available ad libitum was replenished. Hay and water were available in the indoor retreat area at all times. Enrichment in the form of hanging feeders, puzzle balls, and fresh browse was provided daily in the two retreat areas to encourage exploration and foraging.

\section{Grooming Program}

Previously, Lincoln Park Zoo facilitated a more traditional petting zoo program in which visitors were able to enter the goat yard and pet the goats with their hands. Beginning in May 2019, just prior to the start of this study, the program was modified so that visitors could participate in providing care for the goats by grooming them with brushes rather than petting them with bare hands (Figure 2). Fostering such caring behaviors may help guests develop empathy for animals (Young et al., 2018), one of Lincoln Park Zoo's learning objectives. 
Figure 1

Map of the Goat Habitat

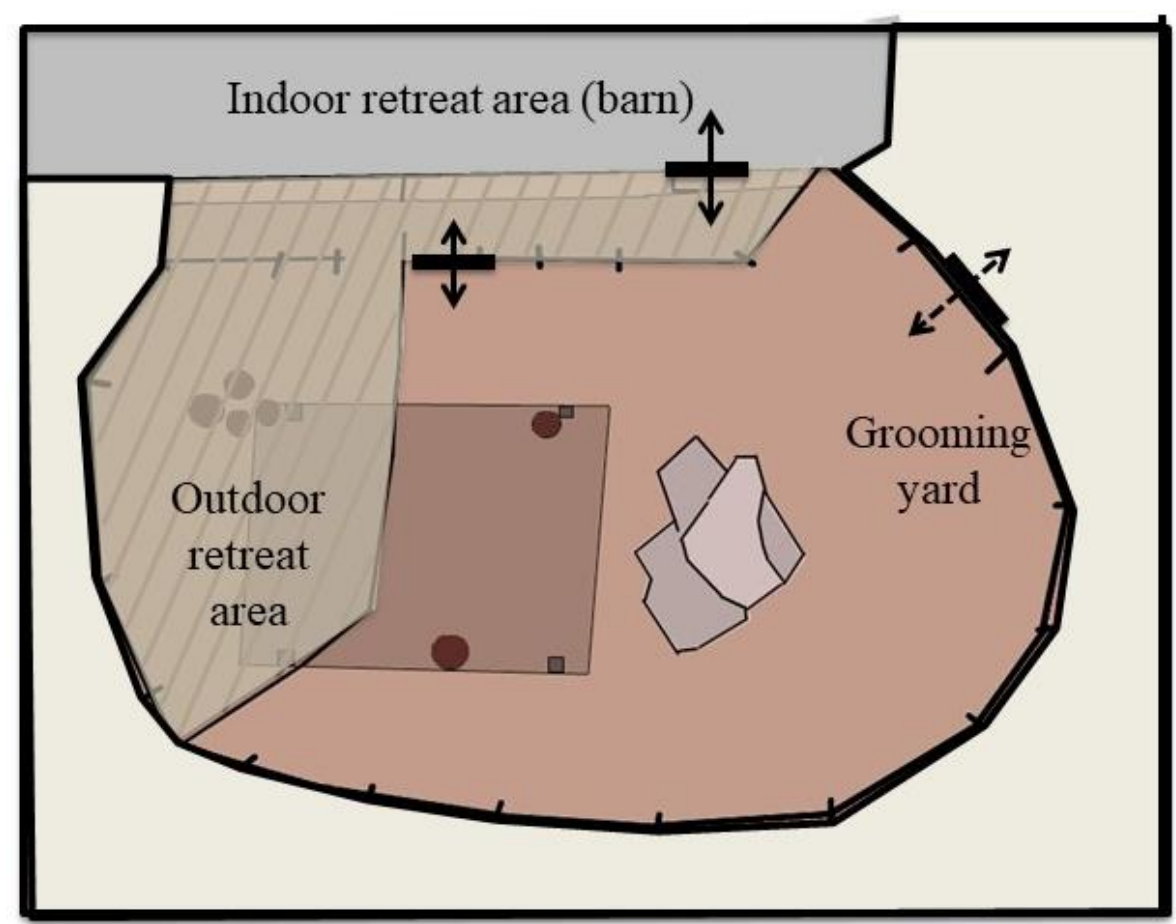

Note. The grooming yard, where visitors and goats could interact, is shown in dark brown. The outdoor retreat area is shown in light brown. Both the outdoor retreat area and the grooming yard enabled access to the shade structure (depicted as rectangle-like structure spanning both areas), logs (brown circles), hay and water. Short, weighted black lines indicate doorways or gates between areas. The dotted arrow indicates where visitors access the yard through a gate. The solid arrows indicate where goats can pass through open doorways between the grooming yard, outdoor retreat area, and indoor retreat area.

Figure 2

Photograph of the Groom-the-Goats Program

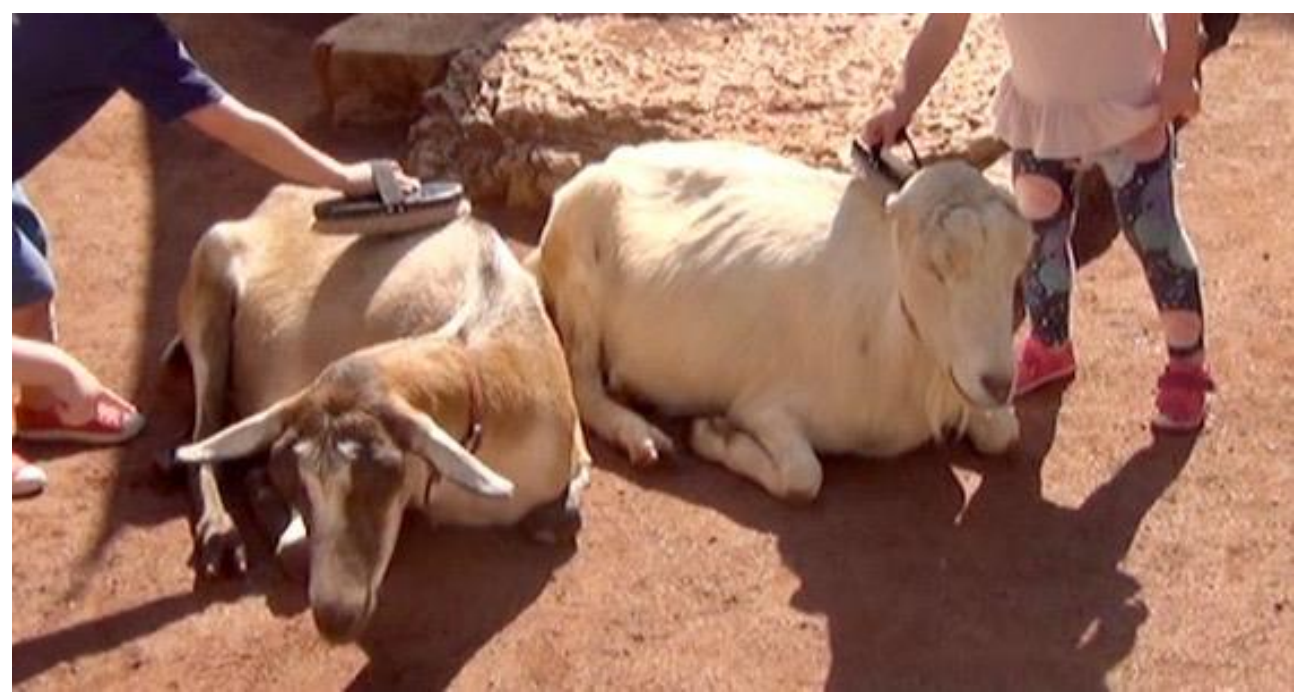

Note. Visitors were instructed to groom the goats with brushes when interacting with the goats to encourage visitors to participate in their care. 
The outdoor yard was open to the public daily from May-October between 10AM to 12PM and 1PM to 4PM. The staff attendant monitored visitor number and behavior, allowing up to 16 visitors into the outdoor yard. Additional visitors formed a line around the exterior perimeter fence of the yard. The goats had access to all areas of their habitat and therefore could choose to be in the presence of visitors in the outdoor yard, or away from visitors in the outdoor retreat space or indoor barn. Visitors were not instructed which goat to groom. The staff attendant provided brushes to visitors upon entering and informed visitors to brush only the back and sides of the goats, in the direction of the grain of the hair. Brushes were standard livestock soft-bristled grooming brushes measuring $8.9 \mathrm{~cm} \mathrm{x} 17.8 \mathrm{~cm}$ (Figure 2).

\section{Data Collection}

We collected behavioral data on weekdays from July-September 2019 using a Canon Vixia HF R10 video camcorder mounted on a portable tripod. The tripod and observer were located outside of the goat yard and moved when necessary to maintain view of the focal goat. Video data collection occurred in the morning (10-11AM) on Mondays, Wednesdays, and Fridays, and in the afternoon (2PM-3:30PM) on Tuesdays and Thursdays. These time frames were chosen to exclude times just before and after the midday feeding. During the data collection windows, we collected multiple 10-min focal animal follow videos. Typically, four to five focal follows were collected in the morning and seven focal follows were collected in the afternoon. In both the morning and afternoon observation periods, the selection of individuals was randomized without replacement to ensure a near equal amount of observation per individual in the morning and afternoon and over the course of the study. Each goat was individually identifiable on footage by its unique markings and/or by collar color. Videos were coded using BORIS software (Version 7.7.3; Friard \& Gamba, 2016), with all-occurrence coding of the goat behaviors defined in Table 1. Additionally, the number of visitors present in the yard and the focal animal's location (in the grooming area, outdoor retreat area, or indoor barn) was recorded on 1-minute intervals cued by a timer using the ZooMonitor application on an iPad (Lincoln Park Zoo, 2020). The number of visitors present in the yard was audibly stated to be available for video coding.

Visitor behavior was also coded from video using BORIS software to better understand how different qualities of an interaction affect goat behavior. Visitor behavior was coded only during interactions with the focal goat. The start of a visitor interaction was defined as any time that a goat and visitor came within 1 meter of each other with contact following, and ended when contact ceased for at least 5 seconds or the goat or visitor walked more than 1 meter away. For each interaction, the following information was recorded: approximate visitor age(s) (toddler, child, adolescent, adult) the approach direction of the visitor(s) when applicable (front, side, behind, multiple directions, unclear), and the grooming style (proper or improper brushing). A proper interaction was qualitatively defined as contact with the brush characterized by gentle sweeping motions in the direction of the goat's hair. An improper interaction was defined as contact with the brush in which the movements were either not gentle, abrupt, did not move in the direction of the goat's hair, and/or used the wrong side of the brush. When an interaction involved multiple visitors in contact with a focal animal simultaneously, the grooming style was coded as improper grooming if any one individual in the group demonstrated improper grooming.

\section{Data Analysis}

A second observer coded $20 \%$ of the video recorded data and obtained greater than $85 \%$ agreement for all behavioral categories. All-occurrence scoring of goat behavior and human behavior was transformed to a binary variable, with each behavior either present or absent in a given one-minute interval. This approach facilitated an investigation of how visitor counts impacted goat behavior on a close temporal scale. The only human-directed goat behavior observed was head-tossing, so the category of human-directed behavior is represented fully by head-tossing (and referred to as such) below. 
Table 1

Ethogram for Goat Behavior

\begin{tabular}{|c|c|c|}
\hline Category & Behavior & Definition \\
\hline \multirow[t]{3}{*}{ Feeding } & Grazing & Animal is pulling small portions of food that are fixed at ground level. \\
\hline & Substrate foraging & $\begin{array}{l}\text { Animal is visually scanning or manipulating loose substrate (e.g., straw, mulch) to } \\
\text { search for food items or moving a minimum of one body's length to acquire small } \\
\text { pieces of food from the substrate (i.e. when food items are scattered across the } \\
\text { ground). }\end{array}$ \\
\hline & Extractive foraging & $\begin{array}{l}\text { Animal is manipulating an object to extract a food item (e.g., includes any food in } \\
\text { enclosed containers like boxes, bags, ice blocks, puzzle feeders, etc.). }\end{array}$ \\
\hline \multirow[t]{3}{*}{ Activity } & Locomotion & Animal is moving at least one body's length in non-stereotypical manner. \\
\hline & $\begin{array}{l}\text { Exploratory } \\
\text { behavior }\end{array}$ & $\begin{array}{l}\text { Animal is engaged with the environment, including inspecting and manipulating items } \\
\text { or performing vigilance behaviors. }\end{array}$ \\
\hline & Object manipulation & Animal is moving a non-fixed object in enclosure using mouth or paws. \\
\hline \multirow[t]{3}{*}{$\begin{array}{l}\text { Self- } \\
\text { Maintenance }\end{array}$} & $\begin{array}{l}\text { Self-maintenance/ } \\
\text { Comfort behaviors }\end{array}$ & $\begin{array}{l}\text { Animal is performing any comfort related behavior including self-directed behaviors, } \\
\text { stretching, yawning, rolling, wallowing, or rubbing against objects. }\end{array}$ \\
\hline & Object rubbing & Animal is rubbing their body against an object. \\
\hline & Salt lick & Animal repeatedly licks mineral block placed in enclosure for that purpose. \\
\hline $\begin{array}{l}\text { Conspecific } \\
\text { Affiliation }\end{array}$ & Affiliative behavior & $\begin{array}{l}\text { Animal performs any non-sexual affiliative behavior, including grooming a social } \\
\text { partner, playing, or social greetings. }\end{array}$ \\
\hline \multirow{8}{*}{$\begin{array}{l}\text { Conspecific } \\
\text { Aggression }\end{array}$} & Contact aggression & Animal physically attacks another individual, including biting, batting, or kicking. \\
\hline & $\begin{array}{l}\text { Non-contact } \\
\text { aggression }\end{array}$ & $\begin{array}{l}\text { Animal performs non-contact aggressive behavior towards another individual, } \\
\text { including threat displays or chasing. }\end{array}$ \\
\hline & Head butting & $\begin{array}{l}\text { Animal turns head sideways and makes contact with another conspecific; may rear } \\
\text { onto hind legs before making contact. }\end{array}$ \\
\hline & Push & $\begin{array}{l}\text { Animal uses some part of their body (usually chest or head) to make contact with } \\
\text { another animal's body in an aggressive manner. }\end{array}$ \\
\hline & Nip & Animal bites another animal's body, usually towards the tail and legs. \\
\hline & $\begin{array}{l}\text { Head tossing } \\
\text { (conspecific) }\end{array}$ & Animal moves its head quickly in the direction of another animal. \\
\hline & Chase & Animal aggressively pursues another individual. \\
\hline & Displacement & $\begin{array}{l}\text { Animal approaches another animal which causes the recipient to move away within } 30 \\
\text { seconds without intervening behaviors (from Stoinski et al., 2004). }\end{array}$ \\
\hline Visitor Directed & $\begin{array}{l}\text { Head tossing } \\
\text { (visitor directed) }\end{array}$ & Animal moves head in a rapid motion towards direction of person. \\
\hline
\end{tabular}

To determine whether goat activity, feeding, self-maintenance behavior, conspecific aggression, or conspecific affiliation was influenced by the number of visitors present anywhere in the grooming yard or the occurrence of a visitor interaction with the focal goat, we created one binomial linear mixed effects model per behavioral category in $\mathrm{R}$ (version 3.6.3, R Core Team, 2020) using the lme4 package (Bates et al., 2015). In all models, random effects of focal goat ID (factor with 7 levels) and focal session ID were included, visitor count in the grooming yard at the start of the one-minute interval was included as a 
continuous numerical variable, and the occurrence of a visitor interaction with the focal was coded as a dichotomous variable per one-minute interval. Reduced models were created to isolate the fixed effects of interest. Specifically, we created two additional binomial linear fixed effects models per behavioral category, one that excluded the number of visitors present in the yard only, and one that excluded the occurrence of visitor interactions only. To determine if the excluded variables significantly influenced model fit, we conducted a likelihood ratio test of the full and reduced models, using the analysis of variance (ANOVA) function in $\mathrm{R}$ and $\chi^{2}$ distribution.

To determine whether head-tossing behavior was influenced by the number of visitors in the grooming yard or the grooming style of the visitor, we created a binomial linear mixed effects model including the random effects of focal goat ID (factor with 7 levels), focal session ID, visitor count in the grooming yard at the start of the one-minute interval as a continuous numerical variable, and proper or improper grooming style as a dichotomous variable. For this model that was specifically focused on the effects of grooming style, only intervals during which a grooming interaction occurred were included. We created one reduced binomial linear fixed effects models that excluded grooming style. To determine if grooming style significantly influenced model fit, we conducted a likelihood ratio test of the full and reduced model, using the analysis of variance (ANOVA) function in $\mathrm{R}$ and $\chi^{2}$ distribution.

To determine whether the number of visitors present in the grooming yard predicted whether the goats chose to be in the yard or in a retreat space, we dichotomously categorized goat location as either in the grooming yard or in a retreat space to use as the dependent variable in a mixed-effects logistic regression model that included subject as a random factor, and temperature and weather (sunny, cloudy, rainy) as continuous and categorical fixed effects, respectively. Temperature was determined using the Weather Channel iOS app (following Wark et al., 2020). Temperature and weather were included to account for the possibility that goats or people were more likely to be in the yard under certain weather conditions (such as warm sunny days). We created a reduced model that retained the other variables but excluded number of visitors in the grooming yard to isolate the contribution of this variable with a likelihood ratio test of the full and reduced model, using the analysis of variance (ANOVA) function in $\mathrm{R}$ and $\chi^{2}$ distribution.

For all models, visual inspections of residual plots did not reveal any obvious deviations from linearity, normality or homoskedasticity. All tests relying on probability distributions to determine significance were two-tailed and $\alpha=.05$.

The study was observational, and no changes were made to animal management practices for the purposes of conducting this research. A large A-frame sign was placed on the walking path approaching the goat yard that read "Photography and Filming Notice. During your visit to Lincoln Park Zoo, you may be filmed, videotaped or photographed by or on behalf of Lincoln Park Zoo. Your entry to the zoo serves as permission for use of your image by Lincoln Park Zoo." Beyond images captured on video, no individually identifiable data were collected on visitors. Video data were stored on external hard drives. The Lincoln Park Zoo Institutional Review Board deemed this study exempt (IRB-19-016).

\section{Results}

Twenty-nine hours of focal follows were conducted over 43 days, resulting in 178 focal follows nearly equally distributed across subjects (range $22-28$ focal follows per subject) and across morning and afternoon observation periods (90 morning follows, 88 afternoon follows). The number of visitors present in the grooming yard ranged from 0 to $16(M=3.14$ visitors, $S D=3.54$, mode $=0)$. A total of 775 human interactions were recorded, $38.5 \%$ of which were coded as involving proper grooming technique. Toddlers were involved in $23.5 \%$ of interactions, children in $19.7 \%$, adolescents in $8.7 \%$, adults in $24.6 \%$, and groups of mixed ages in $23.5 \%$.

Full-null model comparisons revealed that the number of visitors present in the yard was not a significant predictor for any behavioral category. Furthermore, the occurrence of a visitor interaction was not a significant predictor of goat activity. Conspecific aggression and affiliation were not significantly predicted by the number of visitors present in the visitor yard nor by the occurrence of a visitor interaction 
(Table 2). However, the occurrence of visitor interactions was a significant predictor for both feeding behavior (full model $\beta=-1.813$, standard error $(S E)=0.460, z=-3.994, p<.0001$ ) and self-maintenance behavior (full model $\beta=0.464, S E=0.198, z=-2.336, p=.020$ ). The directions of these effects indicate that visitor interactions were associated with a reduction in feeding behaviors and an increase in selfmaintenance behaviors. Considering these significant behavioral changes further, we see that at an individual level, all goats showed a decrease in feeding behavior when people were interacting with them (Figure 3), whereas the change in self-maintenance behavior was more variable (Figure 4).

\section{Table 2}

Full-null Model Comparison Results Summary for Binomial Mixed Effects Models

\begin{tabular}{|c|c|c|c|c|c|}
\hline Model Set & $\begin{array}{l}\text { Predictor } \\
\text { of Interest }\end{array}$ & $\chi^{2}$ & df & $p$-value & Interpretation of Result \\
\hline \multirow{2}{*}{ 1. Activity } & $\begin{array}{l}\text { visitor } \\
\text { count }\end{array}$ & 1.618 & 1 & .203 & $\begin{array}{l}\text { Goat activity did not change dependent upon the number of } \\
\text { visitors present in the yard. }\end{array}$ \\
\hline & $\begin{array}{l}\text { visitor } \\
\text { interaction }\end{array}$ & 0.071 & 1 & .79 & $\begin{array}{l}\text { Goat activity did not change dependent upon whether or not a } \\
\text { direct visitor interaction was occurring. }\end{array}$ \\
\hline \multirow{2}{*}{ 2. Feeding } & $\begin{array}{l}\text { visitor } \\
\text { count }\end{array}$ & 1.363 & 1 & .243 & $\begin{array}{l}\text { Goat feeding did not change dependent upon the number of } \\
\text { visitors present in the yard. }\end{array}$ \\
\hline & $\begin{array}{l}\text { visitor } \\
\text { interaction }\end{array}$ & 18.492 & 1 & $<.001 *$ & $\begin{array}{l}\text { Goat feeding decreased when direct visitor interactions were } \\
\text { occurring. }\end{array}$ \\
\hline \multirow{2}{*}{$\begin{array}{l}\text { 3. Self- } \\
\text { maintenance }\end{array}$} & $\begin{array}{l}\text { visitor } \\
\text { count }\end{array}$ & 2.16 & 1 & .141 & $\begin{array}{l}\text { Goat self-maintenance behavior did not change dependent upon } \\
\text { the number of visitors present in the yard. }\end{array}$ \\
\hline & $\begin{array}{l}\text { visitor } \\
\text { interaction }\end{array}$ & 5.133 & 1 & $.023 *$ & $\begin{array}{l}\text { Goat self-maintenance behavior increased when direct visitor } \\
\text { interactions were occurring. }\end{array}$ \\
\hline \multirow{2}{*}{$\begin{array}{l}\text { 4. Conspecific } \\
\text { aggression }\end{array}$} & $\begin{array}{l}\text { visitor } \\
\text { count }\end{array}$ & 0.162 & 1 & .687 & $\begin{array}{l}\text { Goat aggression did not change dependent upon the number of } \\
\text { visitors present in the yard. }\end{array}$ \\
\hline & $\begin{array}{l}\text { visitor } \\
\text { interaction }\end{array}$ & 2.132 & 1 & .144 & $\begin{array}{l}\text { Goat aggression did not change dependent upon whether or not } \\
\text { a direct visitor interaction was occurring. }\end{array}$ \\
\hline \multirow{2}{*}{$\begin{array}{l}\text { 5. Conspecific } \\
\text { affiliation }\end{array}$} & $\begin{array}{l}\text { visitor } \\
\text { count }\end{array}$ & 1.302 & 1 & .254 & $\begin{array}{l}\text { Goat affiliation did not change dependent upon the number of } \\
\text { visitors present in the yard. }\end{array}$ \\
\hline & $\begin{array}{l}\text { visitor } \\
\text { interaction }\end{array}$ & 1.145 & 1 & .285 & $\begin{array}{l}\text { Goat affiliation did not change dependent upon whether or not a } \\
\text { direct visitor interaction was occurring. }\end{array}$ \\
\hline \multirow[b]{2}{*}{ 6. Head-toss } & $\begin{array}{l}\text { visitor } \\
\text { count }\end{array}$ & 7.129 & 1 & $.008 *$ & $\begin{array}{l}\text { Goat head-tossing behaviors during human interactions } \\
\text { increased as more visitors were present in the yard. }\end{array}$ \\
\hline & $\begin{array}{l}\text { grooming } \\
\text { style }\end{array}$ & 21.807 & 1 & $<.001^{*}$ & $\begin{array}{l}\text { Goat head-tossing behaviors during human interactions were } \\
\text { more frequent when grooming was improper (compared to } \\
\text { proper). }\end{array}$ \\
\hline $\begin{array}{l}\text { 7. Yard vs } \\
\text { retreat space }\end{array}$ & $\begin{array}{l}\text { visitor } \\
\text { count }\end{array}$ & 14.325 & 1 & $<.001 *$ & $\begin{array}{l}\text { Goats were present in the grooming yard more often as the } \\
\text { number of visitors in the yard increased. }\end{array}$ \\
\hline
\end{tabular}

Note. Each row provides the results obtained when comparing the full model with a null model that contained all variables except the predictor of interest. For model sets 1-5, the full model included the effects of goat ID, session ID, visitor count, and whether or not a visitor interaction occurred. For model set 6, the full model included the effects of goat ID, session ID, visitor count and grooming style. For model set 7, the full model included goat ID, temperature, weather, and visitor count. 
Figure 3

Prevalence of Feeding Behavior with and without Human Interaction

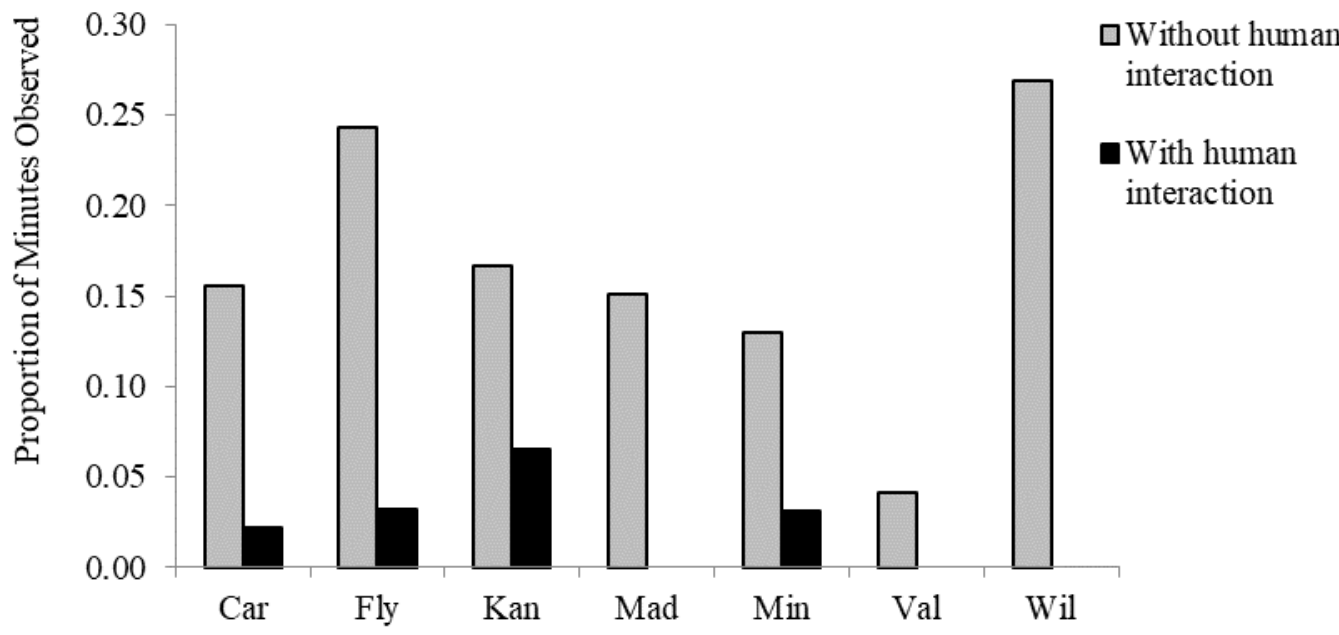

Note. Individual goat's proportion of minutes observed feeding with and without human interaction occurring. Each individual goat was observed feeding more outside of human interactions.

\section{Figure 4}

Prevalence of Self-maintenance Behavior with and without human interaction

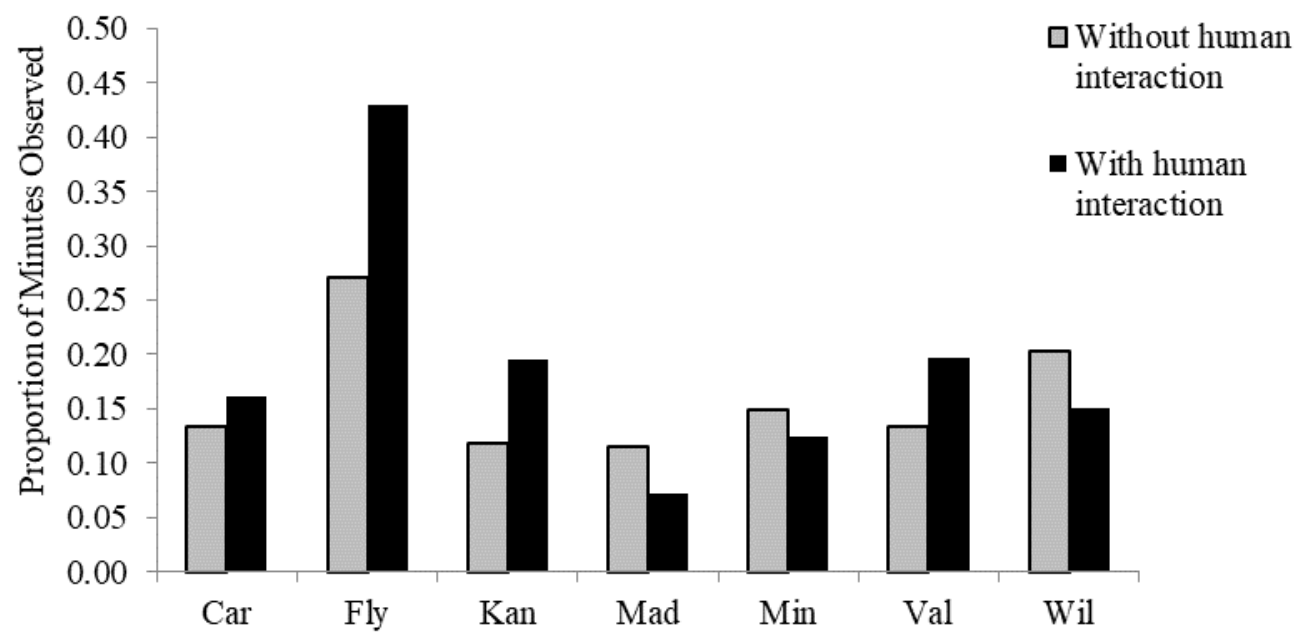

Note. Individual goat's proportion of minutes observed in self-maintenance behaviors with and without human interaction occurring. Although significantly different at a group level, not all individuals showed an increase in self-maintenance behavior when human interactions took place.

An additional binomial linear model considered whether the number of visitors present in the yard and the proper or improper grooming style of the visitor predicted head-tossing (the only humandirected behavior observed). Full-null model comparisons revealed that both visitor count and grooming style were significant predictors of head tossing (Full model visitor count: $\beta=0.167, S E=0.064, z=$ 2.612, $p=.009$; grooming style: $\beta=2.261, S E=0.554, z=4.086, p<.001$ ) The direction of effects revealed that head tossing was more common when a greater number of visitors were in the yard and 
when improper grooming took place. The changes in head-tossing behavior in response to grooming style at an individual animal level are shown in Figure 5.

The investigation of retreat space use revealed that visitor count was a significant predictor of whether goats were in the grooming yard or retreat space, such that goats were more likely to be in the visitor yard as visitor numbers increased (Figure 6; full model visitor count: $\beta=0.188, S E=0.054, z=$ $3.488, p=<.001)$. Temperature and weather were not significant predictors in the full model.

\section{Figure 5}

Prevalence of Head-tossing Behavior During Interactions with Proper and Improper Grooming

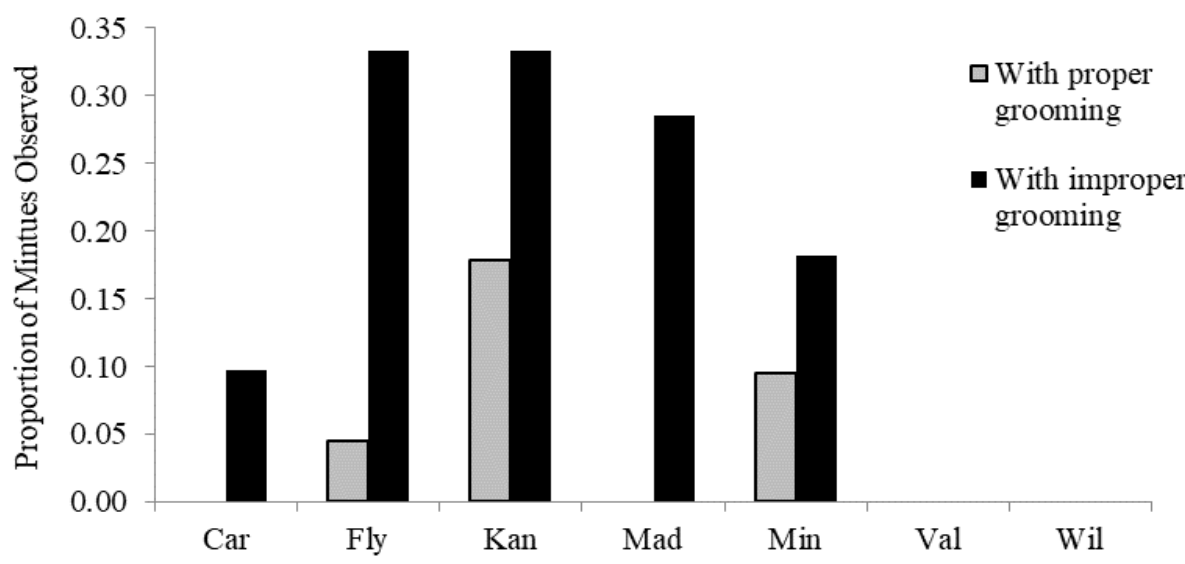

Note. Individual goats' proportion of minutes in which head tossing was observed during interactions characterized by proper and improper grooming. For all goats with head tossing observed, it occurred more often when improper grooming was taking place.

\section{Figure 6}

Relationship Between Visitor Count and Goat Presence in Grooming Yard

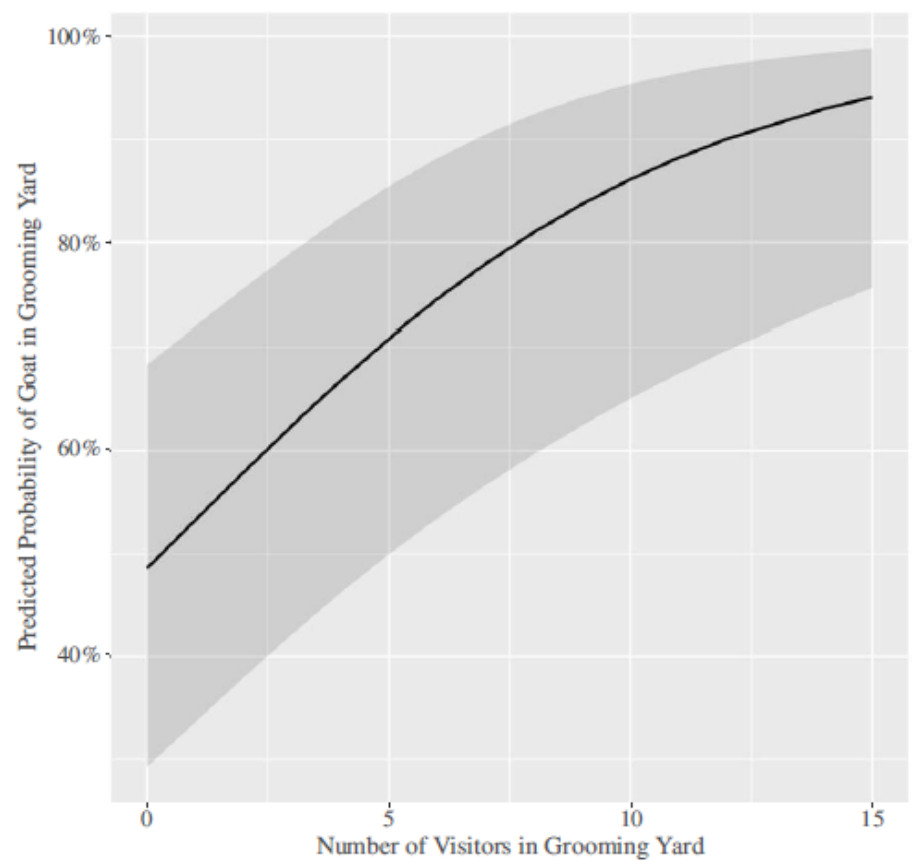

Note. Predicted probability of a goat being in the grooming yard (as opposed to a retreat space) by the number of visitors present in the goat yard, predicted from the full model. 


\section{Discussion}

We considered if and how the behavior of domestic goats changed in response to the presence and behavior of visitors in a zoo-based visitor-interaction program, with the larger goal of inferring the effect of the program on their welfare. Based on previous research demonstrating the beneficial effects of retreat spaces on animal welfare, goats had continuous access to retreat spaces at all times. In this visitorinteraction program, up to 16 visitors entered into the goat yard at one time. We found no change in any behaviors of interest dependent upon the number of visitors present, suggesting that the presence of people in the grooming yard did not impact the goats' welfare. In fact, we found that goats preferred to be in the visitor yard as visitor numbers increased.

We were also interested in whether goat behavior changed during interactions with visitors. We found no changes in conspecific aggression and conspecific affiliation, two types of behaviors that would have likely reflected changes in welfare. We did find that there was a decrease in feeding and increase in self-maintenance behaviors at the time that visitors were in close proximity and interacting with them, however. We included these behaviors in our study to have a better understanding of changes in the goats' behavior that may result from human interaction, although they do not suggest a directional change in welfare per se. Finally, the goats' visitor-directed behavior, specifically head tossing, was more common when more visitors were present and grooming in an improper way.

Taken together, these findings indicate that the mere presence of visitors in the grooming yard had no measurable impact on the goats' behavior, at least up to the maximum allowed in this program and while the goats had the option to retreat. These findings are consistent with previous research, and reinforce the idea that domestic goats may be good candidates for human-visitor interaction programs under these conditions. However, this study takes our knowledge one step further by demonstrating that goats are sensitive to the way that visitors interact with them under these conditions.

Previous research has found that goats, in comparison to other domestic species, may be less influenced by the presence of unfamiliar people (Anderson et al., 2004; Farrand et al., 2014), especially when options to move away from people are provided (Anderson et al., 2002). Considering how animals use their space is a simple but effective way to infer their comfort in the presence of visitors, as animals will generally tend to avoid situations that make them less comfortable if possible (Learmonth et al., 2018; Ramont et al., 2021; Saiyed et al., 2019; Wark et al., 2019). Our results suggest that goats are not averse to the presence of unfamiliar people, and that they may be attracted to them under certain conditions, namely, with the option to retreat and a limit on the maximum number of people present. Previous research on goats (Anderson et al., 2002) and other species (e.g., Brando \& Buchanan-Smith, 201; Kurtcyz, 2015; Ross, 2006; Veasey, 2017) has demonstrated the positive welfare impacts of providing animals the option to retreat or move to different locations. Therefore, we think it is likely that the availability of the retreat space, regardless of its use, influenced the apparent comfort the goats displayed in the presence of visitors.

Although goat behavior did not change based on the presence of visitors in the yard, there were some changes in behavior dependent upon whether visitors in the yard were standing or crouching in their immediate proximity and engaging in some kind of interaction. For example, when interactions were taking place, goats were less often engaged in feeding behavior. This was true at a group level and for each individual goat. This may come about because goats paused their feeding activities when visitors were near them, or because goats moved away from visitors in order to feed. Food was more often available in retreat areas than the yard, so the latter may provide more explanation. Behavioral observations took place outside of primary feeding times, so there is little concern that this change has any serious implications for the goats' caloric intake. The other behavioral change associated with visitor interactions was an increase in self-maintenance behaviors, which included self-directed grooming, stretching, yawning, rolling or rubbing against people or objects (not brushes). This was true at a group level, but not all goats showed this directional change. The uptick that we observed may be due to an actual need to maintain one's physical condition (e.g., lick fur that has been soiled or otherwise affected by visitors), or reflect an affiliative or calm behavioral response to being groomed. 
Importantly, the way in which visitors acted toward the goats did influence goat behavior. In line with previous research demonstrating goats' responsiveness to different stockmanship and handling styles (Jackson \& Hackett, 2007; Waiblinger et al., 2006), we also find that in the zoo environment, where goats are exposed to unfamiliar people on a regular basis, they are more likely to be disturbed and express human-directed aggression in the form of head-tossing behavior when unfamiliar people groom them in an inappropriate, less gentle manner.

Although the change in head-tossing behavior was statistically significant, to put this in context, head-tossing behavior was still relatively infrequent, occurring 53 times in $29 \mathrm{hr}$ of data collection. However, the relationship between head tossing and human behavior suggests that goats are not indifferent to the manner in which the public interacts with them, despite regular interactions and a demonstrated choice to be in the presence of visitors. Based on these results, Lincoln Park Zoo is creating new signage and increasing verbal messaging about how goats prefer to be groomed. Head-tossing behavior allows us a rather straightforward interpretation of a negatively valenced emotional state, indicating that the goat experiences at least a temporary decrease in welfare status during the inappropriate grooming interactions (Mellor et al., 2020; Mendl et al., 2010).

Goats are a gregarious species; individuals tend to stay in close proximity to one another, rarely separating from their group (Miranda-de la Lama \& Mattiello, 2010; Ross \& Berg, 1956). Social isolation induces welfare compromise in goats, as evidenced through behavioral changes and elevated cortisol concentrations (Kannan et al., 2002; Miranda-de la Lama \& Mattiello, 2010). It was beyond the scope of this study to investigate social dependencies of goat space use, but a better understanding of how group dynamics impact goats' comfort in utilizing retreat spaces would be valuable for informing design of interactive spaces. Retreat spaces should be minimally equivalent to the animals in terms of their desirability; for goats this may involve the availability of shade, preferred substrates, food and enrichment. Given the motivation of goats to maintain social cohesion and behavioral synchrony, future work should consider how physical location and visual continuity of retreat spaces is likely to influence goats' evaluation of the spaces as viable respites from human contact areas.

This study provides some direction for designing and managing goat interaction opportunities in a way that enhances welfare. Considering the current results alongside past research, it seems that domestic goats generally fare well with monitored human interaction opportunities when retreat spaces are available and limits are placed on the number or density of people present. These findings are consistent with previous research, and reinforce the idea that domestic goats may be appropriate candidates for human-visitor interaction programs under specific conditions. Additionally, providing visitor training and oversight on how to physically interact with goats to minimize the occurrence of inappropriate contact will likely translate into less undesirable behavior toward humans, and better animal welfare overall.

\section{Acknowledgements}

We thank Mike Murray, Cassy Kutilek, and the Farm-in-the-Zoo Keepers and Dairy Barn Attendants for input and support. We thank Jason Wark, Natasha Wierzal and Sarah Woody for assistance with ethogram development and behavioral coding. We thank the Lincoln Park Zoo Learning Department for information and the Internships Matter Fund for financial support.

Conflict of interest: The authors declare no conflict of interest.

\section{References}

Anderson, U. S., Benne, M., Bloomsmith, M. A., \& Maple, T. L. (2002). Retreat space and human visitor density moderate undesirable behavior in petting zoo animals. Journal of Applied Animal Welfare Science, 5(2), 125-137. 
Anderson, U. S., Maple, T. L., \& Bloomsmith, M. A. (2004). A close keeper-nonhuman animal distance does not reduce undesirable behavior in contact yard goats and sheep. Journal of Applied Animal Welfare Science, 7(1), 59-69.

Bates, D., Mächler, M., Bolker, B., \& Walker, S. (2015). Fitting linear mixed-effects models using lme4. Journal of Staistical Software, 67, 1-48.

Brando, S., \& Buchanan-Smith, H. M. (2018). The 24/7 approach to promoting optimal welfare for captive wild animals. Behavioural Processes, 156, 83-95.

Breuer, K., Hemsworth, P., \& Coleman, G. J. (2003). The effect of positive or negative handling on the behavioural and physiological responses of nonlactating heifers. Applied Animal Behaviour Science, 84(1), 3-22.

Cole, J., \& Fraser, D. (2018). Zoo animal welfare: The human dimension. Journal of Applied Animal Welfare Science, 21(sup1), 49-58.

D’Cruze, N., Khan, S., Carder, G., Megson, D., Coulthard, E., Norrey, J., \& Groves, G. (2019). A global review of animal-visitor interactions in modern zoos and aquariums and their implications for wild animal welfare. Animals, 9(6), 332.

Fallahsharoudi, A., de Kock, N., Johnsson, M., Ubhayasekera, S.J.K.A., Bergquist, J., Wright, D., \& Jensen, P. (2015). Domestication effects on stress induced steroid secretion and adrenal gene expression in chickens. Scientific Reports, 5(1), 1-10.

Farrand, A., Hosey, G., \& Buchanan-Smith, H. M. (2014). The visitor effect in petting zoo-housed animals: Aversive or enriching? Applied Animal Behaviour Science, 151, 117-127.

Fraser, A. F., \& Broom, D. M. (1990). Farm animal behaviour and welfare. CAB International.

Friard, O., \& Gamba, M. (2016). BORIS: a free, versatile open-source event-logging software for video/audio coding and live observations. Methods in Ecology and Evolution, 7(11), 1325-1330.

Hemsworth, P. H., Sherwen, S. L., \& Coleman, G. J. (2018). Human contact. In M. C. Appleby, I.A.S. Olsson, \& F. Galindo (Eds.), Animal welfare (pp. 294-314). CAB International.

Hosey, G., \& Melfi, V. (2010). Human-animal bonds between zoo professionals and the animals in their care: Human-animal bonds in zoos. Zoo Biology, 31(1), 13-26.

Hosey, G., \& Melfi, V. (2015). Are we ignoring neutral and negative human-animal relationships in zoos? Zoo Biology, 34(1), 1-8.

Jackson, K. M., \& Hackett, D. (2007). A note: The effects of human handling on heart girth, behaviour and milk quality in dairy goats. Applied Animal Behaviour Science, 108(3-4), 332-336.

Kannan, G., Terrill, T. H., Kouakou, B., Gelaye, S., \& Amoah, E. A. (2002). Simulated preslaughter holding and isolation effects on stress responses and live weight shrinkage in meat goats. Journal of Animal Science, 80(7), 1771-1780.

Künzl, C., \& Sachser, N. (1999). The behavioural endocrinology of domestication: A comparison between the domestic guinea pig (Cavia aperea $f$. porcellus) and its wild ancestor the wild cavy (Cavia aperea). Hormones and Behavior, 34, 28-37.

Kurtycz, L. M. (2015). Choice and control for animals in captivity. Psychologist, 28(11), 892-894.

Learmonth, M. J., Sherwen, S., \& Hemsworth, P. H. (2018). The effects of zoo visitors on Quokka (Setonix brachyurus) avoidance behavior in a walk-through exhibit. Zoo Biology, 37(4), 223-228.

Lincoln Park Zoo (2020). ZooMonitor (Version 3.2) [Mobile application software]. https://zoomonitor.org.

Melfi, V., \& Hosey, G. (2018). The importance of HAIs, HARs, and HABs. In G. Hosey \& V. Melfi (Eds.), Anthrozoology: Human-animal interactions in domesticated and wild animals, (pp. 142-162). Oxford University Press.

Mellor D. J. (2017). Operational details of the five domains model and its key applications to the assessment and management of animal welfare. Animals, 7(8), 60.

Mellor, D., \& Beausoleil, N. (2015). Extending the 'five domains' model for animal welfare assessment to incorporate positive welfare states. Animal Welfare, 24, 241-253.

Mellor, D. J., Beausoleil, N. J., Littlewood, K. E., McLean, A. N., McGreevy, P. D., Jones, B., \& Wilkins, C. (2020). The 2020 five domains model: Including human-animal interactions in assessments of animal welfare. Animals, 10(10), 1870.

Mellor, D. J., \& Reid, C. S. W. (1994). Improving the well-being of animals in the research environment. Australian and New Zealand Council for the Care of Animals in Research and Teaching, 3-18.

Mendl M., Burman O. H. P. \& Paul, E. S. (2010). An integrative and functional framework for the study of animal emotion and mood. Proceedings of the Royal Society B: Biological Sciences, 277(1696), 2895-2904.

Miranda-de la Lama, G. C., \& Mattiello, S. (2010). The importance of social behaviour for goat welfare in livestock farming. Small Ruminant Research, 90(1-3), 1-10. 
Powell, D. M., Kozlowski, C. P., Clark, J., Seyfried, A., Baskir, E., \& Franklin, A. D. (2020). Physical and physiological indicators of welfare in guinea pigs (Cavia porcellus) serving as ambassador animals. Animals, 10(5), 815.

Price, E. O. (1984). Behavioral aspects of animal domestication. Quarterly Review of Biology, 59, 1-32.

$\mathrm{R}$ Core Team (2020). R: A language and environment for statistical computing (Version 3.6. 3). R Foundation for Statistical Computing. http://www.R-project.org/

Ramont, M., Leahy, M., \& Cronin, K. A. (2021). Domestic animal welfare at the zoo: The impact of an animal visitor interaction program on chickens. Animal Behavior and Cognition, 8(1), 1-14.

Rodriguez, K. E., Herzog, H., \& Gee, N. R. (2020). Variability in human-animal interaction research. Frontiers in Veterinary Science, 7, 619600.

Ross, S. R. (2006). Issues of choice and control in the behaviour of a pair of captive polar bears (Ursus maritimus). Behavioural Processes, 73(1), 117-120.

Ross, S., \& Berg, J. (1956). Stability of food dominance relationships in a flock of goats. Journal of Mammalogy, 37(1), 129-131.

Rushen, J., Taylor, A. A., \& De Passillé, A. M. (1999). Domestic animals' fear of humans and its effect on their welfare. Applied Animal Behaviour Science, 65(3), 285-303.

Saiyed, S. T., Hopper, L. M., \& Cronin, K. A. (2019). Evaluating the behavior and temperament of African penguins in a non-contact animal encounter program. Animals, 9(6), 326.

Sherwen, S. L., \& Hemsworth, P. H. (2019). The visitor effect on zoo animals: Implications and opportunities for zoo animal welfare. Animals, 9(6), 366.

Smith, J. J. (2014). Human-animal relationships in zoo-housed orangutans (P. abelii) and gorillas (G. g. gorilla): The effects of familiarity. American Journal of Primatology, 76(10), 942-955.

Spooner, S. L., Farnworth, M. J., Ward, S. J., \& Whitehouse-Tedd, K. M. (2021). Conservation education: Are zoo animals effective ambassadors and is there any cost to their welfare? Journal of Zoological and Botanical Gardens. 2(1), 41-65.

Veasey, J. S. (2017). In pursuit of peak animal welfare; the need to prioritize the meaningful over the measurable. Zoo Biology, 36(6), 413-425.

Veit, W., \& Browning, H. (2021). Perspectival pluralism for animal welfare. European Journal for Philosophy of Science, 11(1), 1-14.

Waiblinger, S. (2018). Agricultural animals. In G. Hosey \& V. Melfi (Eds.), Anthrozoology (pp. 32-58). Oxford University Press.

Waiblinger, S., Boivin, X., Pedersen, V., Tosi, M.-V., Janczak, A. M., Visser, E. K., \& Jones, R. B. (2006). Assessing the human-animal relationship in farmed species: A critical review. Applied Animal Behaviour Science, 101(3-4), 185-242.

Ward, S. J., \& Melfi, V. (2015). Keeper-animal interactions: Differences between the behaviour of zoo animals affect stockmanship. PLoS One, 10(10), e0140237.

Ward, S. J., \& Sherwen, S. L. (2018). Zoo animals. In G. Hosey \& V. Melfi (Eds.), Anthrozoology: Human-animal interactions in domesticated and wild animals (pp. 81-103). Oxford University Press.

Wark, J. D., Cronin, K. A., Niemann, T., Shender, M. A., Horrigan, A., Kao, A., \& Ross, M. R. (2019). Monitoring the behavior and habitat use of animals to enhance welfare using the ZooMonitor app. Animal Behavior and Cognition, 6(3), 158-167.

Wark, J. D., Wierzal, N. K., \& Cronin, K. A. (2020). Mapping shade availability and use in zoo environments: A tool for evaluating thermal comfort. Animals, 10(7), 1189.

Young, A., Khalil, K. A., \& Wharton, J. (2018). Empathy for animals: A review of the existing literature. Curator: The Museum Journal, 61(2), 327-343.

Zeder, M. A., \& Hesse, B. (2000). The initial domestication of goats (Capra hircus) in the Zagros mountains 10,000 years ago. Science, 287(5461), 2254-2257. 